Marquette University

e-Publications@Marquette

$5-2021$

\title{
Reliability and Performance Improvement of PUC Converter Using a New Single-Carrier Sensor-Less PWM Method with Pseudo Reference Functions
}

\author{
Mostafa Abarzadeh \\ Marquette University \\ Saeed Peyghami \\ Aalborg University \\ Kamal Al-Haddad \\ Ecole de Technologie Superieure \\ Nathan Weise \\ Marquette University, nathan.weise@marquette.edu \\ Liuchen Chang \\ University of New Brunswick
}

See next page for additional authors

Follow this and additional works at: https://epublications.marquette.edu/electric_fac

Part of the Computer Engineering Commons, and the Electrical and Computer Engineering Commons

\section{Recommended Citation}

Abarzadeh, Mostafa; Peyghami, Saeed; Al-Haddad, Kamal; Weise, Nathan; Chang, Liuchen; and Blaabjerg, Frede, "Reliability and Performance Improvement of PUC Converter Using a New Single-Carrier SensorLess PWM Method with Pseudo Reference Functions" (2021). Electrical and Computer Engineering Faculty Research and Publications. 681.

https://epublications.marquette.edu/electric_fac/681 
Authors

Mostafa Abarzadeh, Saeed Peyghami, Kamal Al-Haddad, Nathan Weise, Liuchen Chang, and Frede Blaabjerg

This article is available at e-Publications@Marquette: https://epublications.marquette.edu/electric_fac/681 
Marquette University

e-Publications@Marquette

\section{Electrical and Computer Engineering Faculty Research and Publications/College of Engineering}

This paper is NOT THE PUBLISHED VERSION.

Access the published version via the link in the citation below.

IEEE Transactions on Power Electronics, Vol. 36, No. 5 (May 2021): 6092-6105. DOI. This article is (C) Institute of Electrical and Electronics Engineers and permission has been granted for this version to appear in e-Publications@Marquette. Institute of Electrical and Electronics Engineers does not grant permission for this article to be further copied/distributed or hosted elsewhere without express permission from Institute of Electrical and Electronics Engineers.

\section{Reliability and Performance Improvement of PUC Converter Using a New Single-Carrier Sensor-Less PWM Method with Pseudo Reference Functions}

Mostafa Abarzadeh

SmartD Technologies Inc., Montreal, QC, Canada

Department of Electrical and Computer Engineering, Marquette University, Milwaukee, WI Saeed Peyghami

Department of Energy Technology, Aalborg University, Aalborg, Denmark

Kamal Al-Haddad

Department of Electrical Engineering, École de Technologie Supérieure (ETS), Montreal, QC, Canada Nathan Weise

Department of Electrical and Computer Engineering, Marquette University, Milwaukee, WI, 


\title{
Liuchen Chang
}

Department of Electrical and Computer Engineering, University of New Brunswick, Fredericton, NB, Canada

Frede Blaabjerg

Department of Energy Technology, Aalborg University, Aalborg, Denmark

\section{Keywords}

Capacitor voltage ripple reduction, lifetime improvement, multilevel converter, packed U-cell (PUC) converter, pulsewidth modulation (PWM) method, reliability improvement, sensor-less voltage balancing

\begin{abstract}
:
A new single-carrier sensor-less pulsewidth modulation (PWM) method using suggested pseudo reference functions is proposed for packed U-cell (PUC) converter to improve performance and reliability of the PUC converter. It is composed of one PWM carrier signal and two suggested pseudo reference functions. By employing the proposed modulation method, the PUC dc capacitor voltage ripple is substantially decreased, and faster sensor-less capacitor voltage balancing is obtained. Moreover, the power losses are evenly distributed among all power switches. Consequently, notable reduction of the PUC dc capacitor voltage ripple and even distribution of the power loss among switches enhance the PUC converter's reliability and lifetime. In addition, odd multiples of the switching harmonic clusters are eliminated from the output voltage; thus, the values of output passive filter components are halved. Hence, applying the proposed single-carrier sensor-less PWM method remarkably improves the performance, power density, reliability, and lifetime of the PUC converter and notably simplifies implementation of the switching pattern. Provided experimental results and comparisons as well as reliability analysis verify the viability and effectiveness of the proposed PWM method.
\end{abstract}

\section{SECTION I. Introduction}

Multilevel converters (MLCs) are commonly utilized in various industrial applications as a promising solution to improve output voltage quality and performance of power electronic converters [1]-[2][3]. Among different MLCs, the packed U-cell (PUC) converter has been introduced to provide seven- or five-level output voltage with less number of components. As shown in Fig. 1, it is formed by only two low-frequency (LF) power switches, four high-frequency (HF) power switches, one dc capacitor, and one dc power supply [4], [5]. Hence, among other suggested MLCs, the PUC converter is more competitive, especially for single-phase applications. Various modulation and control methods have been presented for the PUC converter to provide suitable output voltage and regulate the dc capacitor voltage to a desired value [6]-[7][8][9][10][11][12][13]. 


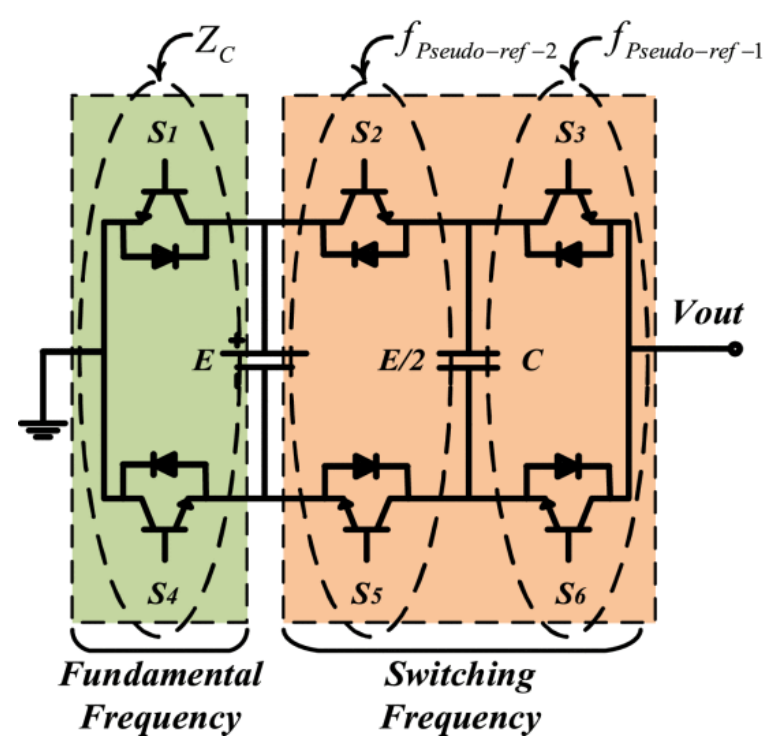

Fig. 1. Topology of the PUC converter.

The suggested modulation and control techniques for the PUC converter can be classified into closedloop and sensor-less pulsewidth modulation (PWM) methods. A six-band hysteresis control method [6] and finite control set model predictive controllers [7], [8] have been proposed for the PUC converter. However, all these methods require a voltage sensor and closed-loop control to balance the dc capacitor voltage. Moreover, they suffer from variable switching frequency and sporadic output voltage harmonic spectrum, which cause major issues in design of the output passive filter.

In [9]-[10][11][12][13], the sensor-less carrier-based PWM switching methods has been presented for the PUC converter. In [9], a phase disposition PWM method with sensor-less control of the dc capacitor voltage has been introduced for the PUC converter. It comprises four level-shifted PWM carrier signals, a switching states table, and five logic gates. In [10] and [11], the space vector PWM and the phaseshifted PWM (PSPWM) methods have been presented as sensor-less control of the PUC converter, respectively. The introduced PSPWM method in [11] consists of four PSPWM carrier signals and 12 If-Else loops. Thus, to implement the presented methods in [9] and [11], four level/PSPWM timers are required. Moreover, the presented method in [9] needs a switching states table, six If-Else loops, as well as five logic gates, and the suggested method in [11] requires 12 If-Else loops. Furthermore, in suggested methods in [9]-[10][11], charging/discharging of the dc capacitor is balanced in each fundamental period of the output voltage [12], [13]. Therefore, by applying the presented methods in [9]-[10][11] to the PUC converter, the size and voltage ripple of the dc capacitor depend on the output voltage fundamental frequency and the load current. Consequently, a large dc capacitor is required to form a suitable output voltage waveform. Sensor-less modulation methods using two level-shifted PWM carriers and logic gates have been presented in [12] and [13]. In the presented methods in [12] and [13], not only the number of required PWM carrier signals is halved but also the size of the dc capacitor is reduced by balancing charging/discharging of the dc capacitor in each PWM period. However, they require two level-shifted PWM carrier signals, five comparators, and six logic gates. The relation between the size of the dc capacitor, the dc capacitor voltage ripple, and load current has been described in [13] in detail. Moreover, comparison between various PWM methods for the PUC converter from aspects of the size of dc capacitor, the dc capacitor voltage ripple, and the value of the 
output passive filter components has been presented in [13]. Moreover, not only do the abovementioned aspects have crucial impact on the converter performance, but also the converter reliability as its long-term viability is of paramount importance.

The converter lifetime and reliability, especially the components' wear-out, can be affected by the device hardware, and converter control and switching algorithms [14]. The impact of hardware can be incorporated by the appropriate lifetime model. In addition, the control impact depends on different dynamics with wide time scales from switching frequency to slow dynamics such as power management dynamics. This is due to the fact that the aging of a device material depends on the heat dissipation and hot-spot temperature. Meanwhile, the temperature in power converters is a consequence of switching frequency, switching algorithm, loading of the converter, ambient temperature, and thermal couplings among different components inside the converter enclosure [14]. The loading of a converter can be determined by its application and mission profile. Hence, the converter reliability remarkably depends on the mission profile (including loading, ambient temperature, vibration, etc.) and its control algorithms [14]-[15][16][17][18][19][20][21][22]. Notably, in the aforementioned techniques for the PUC converter control, the converter reliability has not been taken into consideration.

In this article, a novel single-carrier sensor-less PWM method using two pseudo reference functions is proposed for the PUC converter to overcome the above-mentioned drawbacks and to improve the performance and reliability of the PUC converter. The major advantages of the proposed single-carrier sensor-less PWM method are summarized as follows:

1. easy to implement and lower computational burden by utilizing only one PWM carrier signal, two comparators, and two suggested pseudo reference functions;

2. notable reduction of the value and voltage ripple of the dc capacitor;

3. faster self-balancing of dc capacitor voltage at start-up;

4. amended output voltage waveform by eliminating the odd multiples of switching harmonic clusters from the output voltage spectrum;

5. halving the required output passive filter components values;

6. equal distribution of the conduction and switching power losses between HF power devices;

7. higher reliability and longer lifetime for various applications.

To further evaluate and verify the impact of the proposed modulation method on the PUC converter performance, lifetime, and reliability, a comparative study between the proposed and traditional PWM methods for the PUC converter is performed. Moreover, the PUC converter reliability is predicted for different applications, and its performance under the traditional and proposed switching algorithms are compared from components' wear-out point of view.

In the following, the proposed single-carrier sensor-less decomposed modulation method and its theoretical and mathematical analyses are described in Section II. The applied reliability prediction methodology is presented in Section III. Section IV performs the numerical analyses of the PUC converter reliability for various applications. The experimental results and comparisons from various aspects are presented in Section V. Finally, Section VI provides the conclusion. 


\section{SECTION II. Proposed Single-Carrier Sensor-Less PWM Method for the PUC}

\section{Converter}

In this section, theoretical and mathematical analyses of the proposed switching algorithm as well as its performance are presented in detail.

\section{A. Switching Pattern of the Proposed Single-Carrier Sensor-Less PWM Method}

Table I presents all the possible switching states, the output voltage levels, and the dc capacitor charging/discharging modes in the PUC converter. In Table I, the switch $S X$ is on and off when it is 1 and 0 , respectively.

TABLE I Switching States of the PUC Converter

\begin{tabular}{|l|l|l|l|l|l|}
\hline Switching State & S1 & S2 & S3 & $V_{\text {out }}$ & Capacitor Charge/Discharge \\
\hline$V_{1}$ & & 0 & 0 & $-E$ & No effect \\
\hline$V_{2}$ & & 0 & & $-E / 2$ & Charge \\
\hline$V_{3}$ & 1 & 1 & 0 & $-E / 2$ & Discharge \\
\hline$V_{4}$ & & & & 0 & No effect \\
\hline$V_{5}$ & 0 & 0 & 0 & 0 & No effect \\
\hline$V_{6}$ & 0 & 0 & & $+E / 2$ & Discharge \\
\hline$V_{7}$ & 0 & & 0 & $+E / 2$ & Charge \\
\hline$V_{8}$ & 0 & & & $+E$ & No effect \\
\hline
\end{tabular}

Fig. 2 presents the proposed single-carrier sensor-less PWM method. As shown in Fig. 2, the suggested pseudo reference functions are defined to provide the reference signals for different parts of the PUC converter, which results in using only one PWM carrier signal, reduced dc capacitor voltage ripple, sensor-less voltage balancing of the dc capacitor, equal power losses distribution between switches, and improved output voltage spectrum.

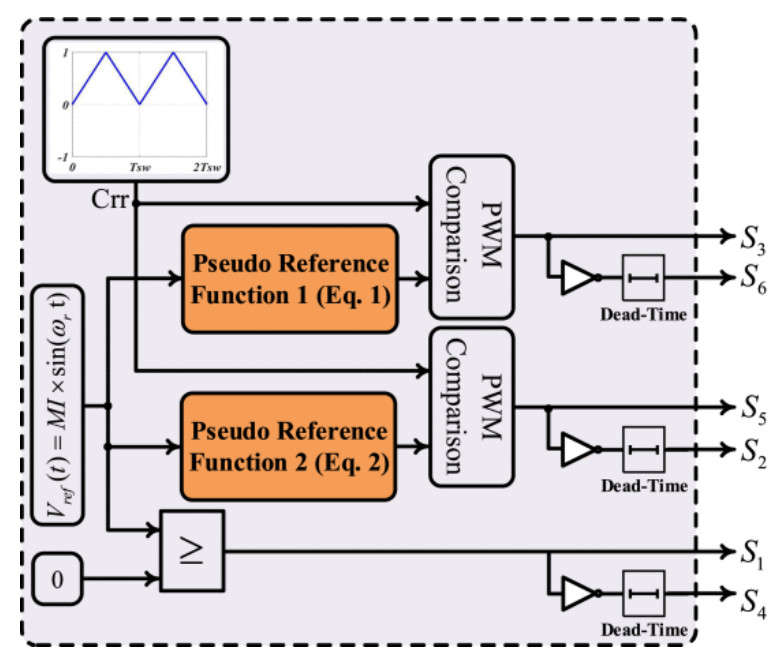

Fig. 2. Proposed single-carrier sensor-less PWM method using pseudo reference functions.

Two suggested pseudo reference functions used in the proposed switching scheme shown in Fig. 2 are expressed as 


$$
\begin{aligned}
& f_{\text {Pseudo-ref-1 }}=\left\{\begin{array}{cc}
V_{\text {ref, }}, & V_{\text {ref }} \geq 0 \\
1+V_{\text {ref }}, & V_{\text {ref }}<0
\end{array}\right. \\
& f_{\text {Pseudo-ref-2 }}=\left\{\begin{array}{cc}
1-V_{\text {ref }}, & V_{\text {ref }} \geq 0 \\
-V_{\text {ref }}, & V_{\text {ref }}<0
\end{array}\right.
\end{aligned}
$$

(1)(2)

where $V_{\text {ref }}$ is the input reference signal. $f_{\text {Pseudo-ref-1 }}$ and $f_{\text {Pseudo-ref-2 }}$ provide the modified reference signals for $\left(S_{3}, S_{6}\right)$ and $\left(S_{2}, S_{5}\right)$, respectively. The outputs of $f_{\text {Pseudo-ref-1 }}$ and $f_{\text {Pseudo-ref-2 }}$ are intersected with one triangular carrier signal to generate switching signals for $\left(S_{3}, S_{6}\right)$ and $\left(S_{2}, S_{5}\right)$ switches.

In addition, a zero-crossing detector is defined to generate switching signals for $\left(S_{1}, S_{4}\right)$ switches. Hence, $\left(S_{1}, S_{4}\right)$ commutate at the fundamental frequency. The zero-crossing detector is defined as

$$
\begin{gathered}
Z_{C}= \begin{cases}1, & V_{\text {ref }} \geq 0 \\
0, & V_{\text {ref }}<0\end{cases} \\
S_{1}=\overline{S_{4}}=Z_{C} .
\end{gathered}
$$

(3)(4)

As shown in Figs. 1 and $2, Z_{C}, f_{\text {Pseudo-ref-2 }}$, and $f_{\text {Pseudo-ref-1 }}$ are used to generate $\left(S_{1}, S_{4}\right),\left(S_{2}, S_{5}\right)$, and $\left(S_{3}, S_{6}\right)$, respectively. The switching pattern of the proposed modulation method, the defined pseudo functions outputs, and the output voltage waveforms are shown in Fig. 3.

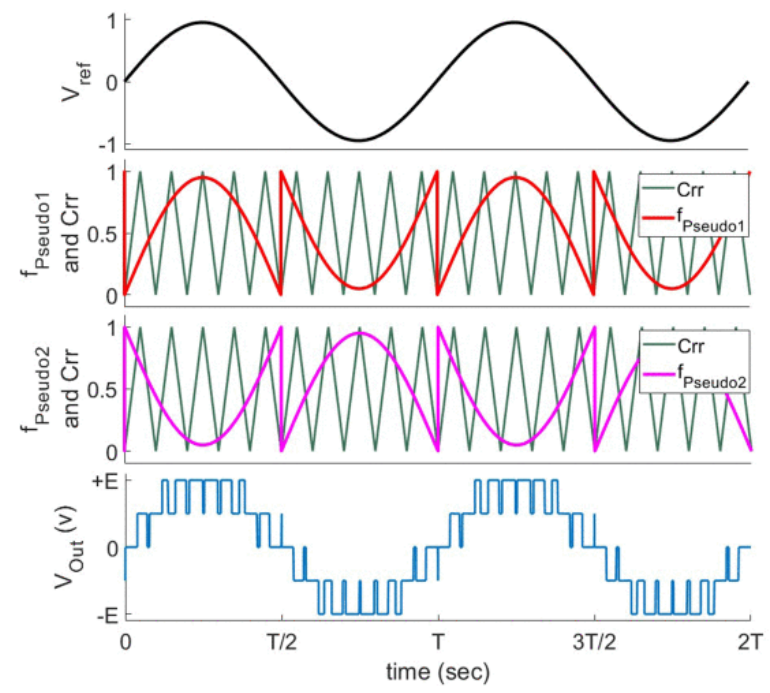

Fig. 3. Switching pattern of the proposed modulation method, the defined $f_{\text {Pseudo-ref-1 }}$ and $f_{\text {Pseudo-ref- } 2}$ pseudo functions outputs, and the PUC output voltage.

The theoretical and mathematical analyses of the above-mentioned advantages of the proposed modulation method in comparison to the traditional switching method are presented in the following parts.

\section{B. Sensor-Less Voltage Balancing of PUC Converter Capacitor}

As illustrated in Table I, the PUC capacitor is charged and discharged based on $\left(S_{2}, S_{5}\right)$ and $\left(S_{3}, S_{6}\right)$ redundant switching states at the output voltage levels of $\pm E / 2$. In the capacitor, the relation among 
load current $\left(i_{l}\right)$, the quantity of charge $\left(Q_{\text {charge }}\right)$ and quantity of discharge $\left(Q_{\text {discharge }}\right)$, and the PWM carrier period $\left(T_{C}\right)$ are expressed as [23]

$$
\begin{aligned}
& i_{l}=\mathrm{dq} / \mathrm{dt} \\
& d t=\frac{\left|T_{C}-t_{\mathrm{on}-S 3}\right|}{2}-\frac{\left|T_{C}-t_{\mathrm{on}-S 2}\right|}{2} \\
& d q=\frac{\left|t_{\mathrm{on}-S 2}-t_{\mathrm{on}-S 3}\right|}{2} \cdot i_{l}
\end{aligned}
$$

$(5)(6)(7)$

where $t_{\mathrm{on}-S 2}$ and $t_{\mathrm{on}-S 3}$ are $S_{2}$ and $S_{3}$ turn-on times, respectively. Hence, the capacitor is automatically regulated to its desired value when $S_{2}$ and $S_{3}$ turn-on times are equal. Accordingly, as presented in Fig. 4, the intersection of the triangular PWM carrier signal $\mathrm{Crr}$ and two suggested decomposed $f_{\text {Pseudo-ref-1 }}$ and $f_{\text {Pseudo-ref-2 }}$ pseudo reference functions outputs provides equal turnon times for $S_{3}$ and $S_{2}$. Therefore, the capacitor charge and discharge quantities $\left(Q_{\text {charge }}\right.$ and $Q_{\text {discharge }}$ ) are balanced in each PWM period and sensor-less voltage balancing of the capacitor is obtained.

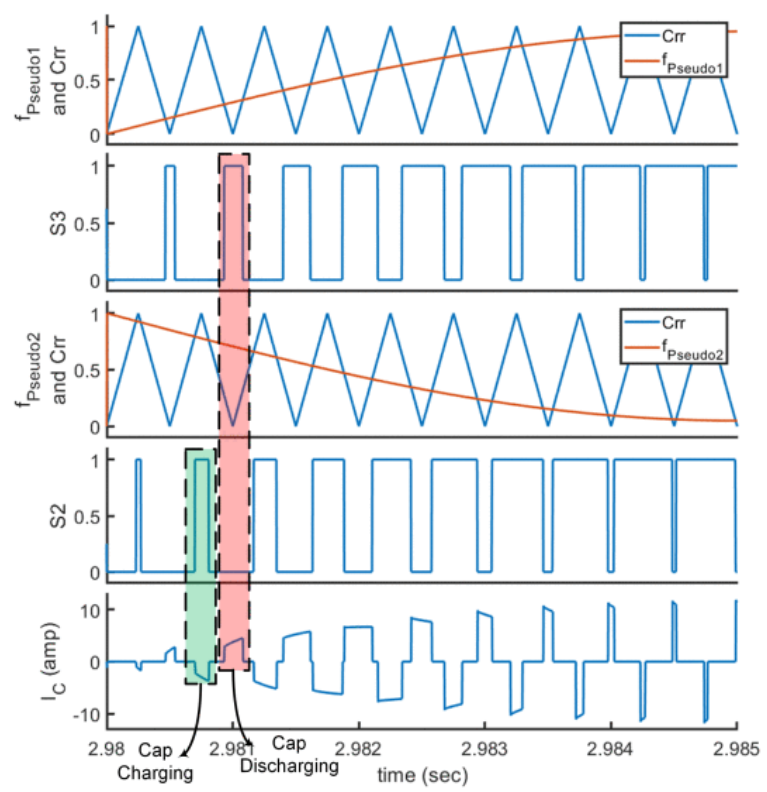

Fig. 4. Balancing process of the $Q_{\text {charge }}$ and $Q_{\text {discharge }}$ of the PUC converter capacitor in each PWM period by applying the proposed single-carrier PWM method with defined pseudo functions.

Moreover, in order for frequency domain analysis of capacitor sensor-less voltage balancing process in the PUC converter, a decoupled mathematical model of the PUC converter is defined by exploiting the equivalent two-port switching circuit theory presented in [24] and [25]. Hence, the proposed singlecarrier sensor-less switching pattern of the PUC converter can be decoupled into the total switching function $\left(s_{t}\right)$ and the difference switching function $\left(s_{d}\right)$ as presented in Fig. 5. 


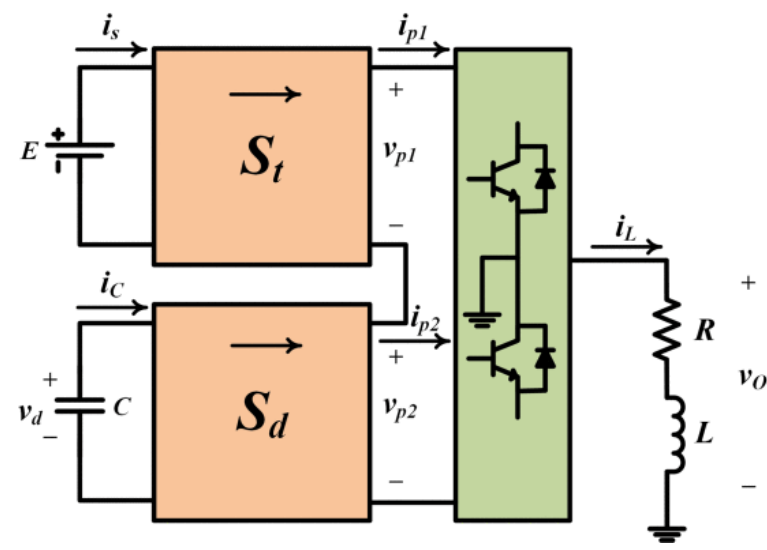

Fig. 5. Equivalent decoupled circuit of the PUC converter by using $d$ and $t$ parameters.

In Fig. $5, v_{d}$ is the voltage difference between the desired and actual values of the capacitor voltage and is determined by (8). Then, the corresponding difference switching function $\left(s_{d}\right)$ to $v_{d}$ is defined by (9) to represent the relevant switching function to the capacitor voltage unbalance

$$
\begin{gathered}
v_{d}=\frac{E}{2}-v_{C} \\
s_{d}=\frac{1}{2}\left\{s_{2}-s_{3}\right\} .
\end{gathered}
$$

(8)(9)

Moreover, the corresponding total switching function $\left(s_{t}\right)$ is expressed as

$$
s_{t}=\frac{1}{2}\left\{s_{2}+s_{3}\right\}
$$

where

$$
s_{i}=\left\{\begin{array}{c}
1, \text { if } S_{2} \text { or } S_{3} \text { isON } \\
-1, \text { if } S_{5} \text { or } S_{6} \text { is ON. }
\end{array} \text { for } i=2,3\right.
$$

As presented in Fig. 5 , the proposed switching pattern of the PUC converter is decoupled to $s_{t}$ and $s_{d}$ two-port switching circuits. Based on the two-port switching circuit theory, the relation between input and output of the presented two-port switching circuits $S_{t}$ and $S_{d}$ are expressed as

$$
\begin{gathered}
\left\{\begin{array}{l}
V_{p 1}(\omega)=S_{t}(\omega) * E(\omega) \\
I_{s}(\omega)=S_{t}(\omega) * I_{p 1}(\omega)
\end{array}\right. \\
\left\{\begin{array}{l}
V_{p 2}(\omega)=S_{d}(\omega) * V_{d}(\omega) \\
I_{C}(\omega)=S_{d}(\omega) * I_{p 2}(\omega)
\end{array}\right.
\end{gathered}
$$

where $*$ is the convolution operator in the frequency domain. With regard to the fact that $E(\omega)$ and $V_{d}(\omega)$ are dc values in the steady-state condition, they can be considered as constant values in (12) 
and (13). Hence, as presented in Fig. 5, the load current and the capacitor current in the frequency domain are determined as

$$
\begin{aligned}
I_{L}(\omega) & =\frac{V_{O}(\omega)}{Z(\omega)}=\frac{V_{p 1}(\omega)+V_{p 2}(\omega)}{Z(\omega)} \\
I_{C}(\omega) & =-I_{L}(\omega) * S_{d}(\omega) \\
& =-\left(\frac{E \cdot S_{t}(\omega)+V_{d} \cdot S_{d}(\omega)}{Z(\omega)}\right) * S_{d}(\omega) .
\end{aligned}
$$

Hence, (15) is solved for the steady-state condition in which $\omega=0$. In order to prove the self-balancing of the capacitor voltage to its desired value, the capacitor current in steady-state condition should be zero, and then (15) is solved for $\left.I_{C}(\omega)\right|_{\omega=0}=0$. Thus

$$
\frac{V_{d}}{E}=\frac{\operatorname{Re}\left\{\int_{0}^{\infty} S_{t}(\xi) Z(\xi) \overline{S_{d}(\xi)} d \xi\right\}}{\operatorname{Re}\left\{\int_{0}^{\infty} \frac{\left|S_{d}(\xi)\right|^{2}}{Z(\xi)} d \xi\right\}} .
$$

Equation (16) presents the capacitor voltage unbalance of the PUC converter controlled by the proposed single-carrier sensor-less modulation method. In order to minimize the capacitor voltage unbalance, (16) should be minimized. Hence, the numerator of (16) should be zero to guarantee the self-balancing of the capacitor voltage. The numerator of (16) will be zero if

$$
\left|S_{t}(\omega)\right|\left|S_{d}(\omega)\right| \approx 0 .
$$

Equation (17) is satisfied if the switching frequency is high enough in comparison to the fundamental frequency. Accordingly, with regard to (7), (16), and (17), the PUC converter capacitor voltage selfbalancing is proved and obtained in steady-state condition by employing the proposed single-carrier sensor-less modulation method with defined pseudo functions.

Thus, by employing the proposed single-carrier sensor-less modulation method, the dc capacitor voltage ripple is determined as

$$
V_{\text {ripple }}=\frac{I_{\text {peak }}}{C \times 2 f_{\text {SW }}}
$$

where $C$ is the dc capacitor value, $f_{\mathrm{SW}}, I_{\text {peak }}$, and $V_{\text {ripple }}$ are switching frequency, load current peak value, and maximum voltage ripple of the dc capacitor, respectively. Considering (18), the dc capacitor voltage ripple is decreased by a factor of $f_{\mathrm{SW}} / f_{0}$ is the fundamental frequency) in comparison to values reported in the literature [9]-[10][11]. Hence, the dc capacitor voltage ripple is significantly decreased by applying the proposed single-carrier switching method. 


\section{Output Voltage Harmonic Spectrum Analysis and the Output LC Filter Components Values Calculation}

As presented in Fig. 1, the two new defined pseudo functions are used to generate corresponding switching signals of $\left(S_{2}, S_{5}\right)$ and $\left(S_{3}, S_{6}\right)$ power switches. Therefore, as discussed in [26], Fourier series expansion of $S_{2}$ and $S_{3} \mathrm{HF}$ switching function are expressed as

$$
\begin{aligned}
& \begin{array}{c}
f_{\text {Pseudo-ref-2 }}(t)=s_{2}(t) \\
=\frac{1}{2} A_{00}+\sum_{n=1}^{\infty}\left\{A_{0 n} \cos \left(n \omega_{r} t\right)+B_{0 n} \sin \left(n \omega_{r} t\right)\right\}
\end{array} \\
& +\sum_{m=1}^{\infty}\left\{A_{m 0} \cos \left(m \omega_{s} t\right)+B_{m 0} \sin \left(m \omega_{s} t\right)\right\} \\
& +\sum_{m=1}^{\infty} \sum_{n= \pm 1}^{ \pm \infty}\left\{A_{m n} \cos \left(m \omega_{s} t+n \omega_{r} t\right)\right) \\
& =\frac{1}{2 \pi^{2}} \int_{-\pi}^{\pi} \int_{-\pi}^{\pi} f_{\text {Pseudo-ref-2 }}(x, y) \cos (m x+n y) d x d y \\
& x=m \omega_{s} t y=n \omega_{r} t \\
& f_{\text {Pseudo-ref-1 }}(t)=s_{3}(t) \\
& =\frac{1}{2} A_{00}+\sum_{n=1}^{\infty}\left\{A_{0 n} \cos \left(n \omega_{r} t\right)+B_{0 n} \sin \left(n \omega_{r} t\right)\right\} \\
& +\sum_{m=1}^{\infty}\left\{A_{m 0} \cos \left(m \omega_{s} t\right)+B_{m 0} \sin \left(m \omega_{s} t\right)\right\} \\
& +\sum_{m=1}^{\infty} \sum_{n= \pm 1}^{ \pm \infty}\left\{A_{m n} \cos \left(m \omega_{s} t+n \omega_{r} t\right)\right) \\
& =\frac{1}{2 \pi^{2}} \int_{-\pi}^{\pi} \int_{-\pi}^{\pi} f_{\text {Pseudo-ref-1 }}(x, y) \cos (m x+n y) d x d y \\
& x=m \omega_{s} t y=n \omega_{r} t .
\end{aligned}
$$

$(19)(20)(21)(22)$

In (19) and (21), the first term represents the dc offset, the second term represents fundamental component and baseband harmonics, the third term represents the carrier harmonics, and the fourth term represents the sideband harmonics of the modulated reference signal. 
As described in Section II-B, with regard to Fig. 5 and (9) and (10), the total switching function $\left(s_{t}\right)$ and difference switching function $\left(s_{d}\right)$ are defined for the equivalent decoupled circuit of the PUC converter by using $d$ and $t$ parameters. It is worth mentioning that as proved in Section II-B, the difference switching function $\left(s_{d}\right)$ represents the voltage balancing of the capacitor and the total switching function $\left(s_{t}\right)$ represents the output voltage harmonic spectrum. Considering (9) and (10), harmonics of $s_{t}$ and $s_{d}$ total and difference switching functions for $f_{\mathrm{SW}}=10 \mathrm{kHz}$ and $M=0.9$ are shown in Fig. 6 . As presented in Fig. $6, s_{t}$, which presents the output voltage harmonic spectrum, has harmonic clusters at $2 k \cdot f_{\mathrm{SW}}$ where $k$ is an integer number. Hence, odd multiples of the switching harmonic clusters are canceled out at the output voltage frequency spectrum and the first switching harmonic cluster of the output voltage is shifted to $2 f_{\mathrm{SW}}$. Therefore, the amended output voltage spectrum is obtained by applying the proposed single-carrier sensor-less modulation method.

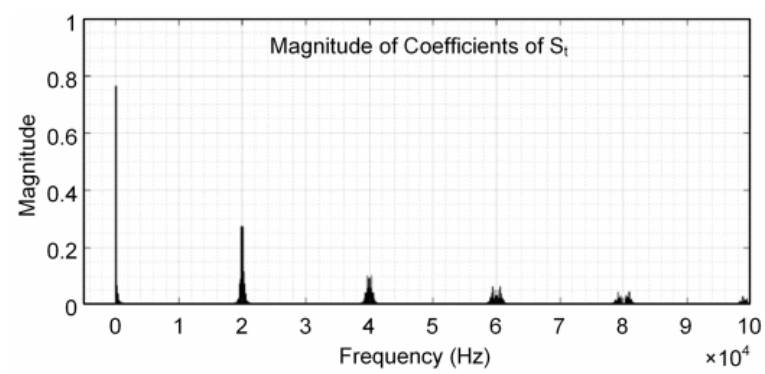

(a)

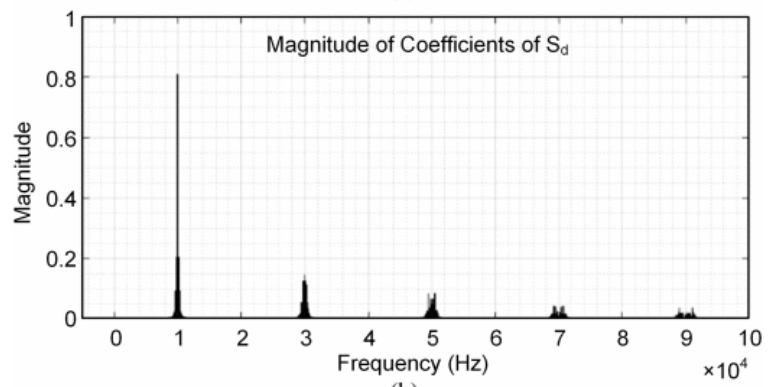

(b)

Fig. 6. Harmonics of (a) $s_{t}$ and (b) $s_{d}$, the total and difference switching functions for $f_{\mathrm{SW}}=10 \mathrm{kHz}$ and $M=$ 0.9 .

In addition, as shown in Fig. $6, s_{d}$, which presents charging/discharging of the capacitor, has the switching harmonic clusters at $(2 k-1) \cdot f_{\mathrm{SW}}, k=1,2, \ldots$ Hence, the PUC converter capacitor is charged and discharged by switching frequency and the even multiples of the switching harmonic clusters are canceled out at the difference switching function $\left(s_{d}\right)$. Hence, the total switching function $\left(s_{t}\right)$ and difference switching function $\left(s_{d}\right)$ are completely decoupled, and considering (17), the sensorless capacitor voltage balancing is also obtained by applying the proposed single-carrier sensor-less modulation method.

As described in [3] and [13] in detail, the output filter inductor and capacitor values are obtained as

$$
\begin{aligned}
L & =\frac{V_{\mathrm{DC}}}{8(n-1) \cdot \Delta I_{L} \cdot f_{1 \text { stSWHarmonic }}} \\
C & =\frac{1}{\left(\frac{2 \pi \cdot f_{1 \text { stSWHarmonic }}}{4}\right)^{2} \cdot L} .
\end{aligned}
$$


As presented in (23) and (24), since $f_{1 \text { stSWHarmonic }}$ is doubled by applying the proposed modulation method, both inductor and capacitor values are halved in comparison with employing the traditional modulation method for the PUC converter.

Moreover, by employing the proposed modulation method using the suggested pseudo reference functions, $\left(S_{2}, S_{5}\right)$ and $\left(S_{3}, S_{6}\right)$ switching signals are equally distributed in each fundamental period, which results in equal switching and conduction losses, as well as balanced power dissipation for all switching devices in the PUC converter.

\section{SECTION III. Applied Reliability Prediction Methodology}

Reliability of an item/a system is defined as a measure of its ability to fulfill its functionality with a desired performance over a specified time [27]. The system or item performance can be defined as the probability of its survival. Hence, reliability can be measured by the probability of survival within a specified time. For instance, if system reliability is $R$ at the time of $T$ in years, the system first failure will occur after $T$ years with the probability of $(1-R)$. Moreover, the time period of $T$ is known as $B_{100(1-R)}$ lifetime.

The reliability of power converters can be predicted by the reliability of its fragile components. Following field data and industrial experiences, the semiconductor devices and capacitors are the most vulnerable components of converters [28]-[29][30][31]. They are prone to wear-out failures [21], [22], thus limiting converters lifetime. In the following, the reliability estimation procedure of converter components is presented.

Conventionally, converter reliability has been predicted based on historical data provided in the Military Handbook 217 (MIL-HDBK-217). This approach has been later updated because of its outdated data for new devices, vagueness of the failure mechanisms, and exclusion of operation conditions. Hence, different versions of this method have been provided such as Siemens SN29500, Telcordia SR322, and RDF-2000. Afterward, the International Electrotechnical Commission (IEC) released a technical report of IEC TR-62380 [21], which considers the failure mechanisms and operating conditions for failure rate prediction. However, the provided data are still outdated and the failure mechanisms are not properly included in IEC TR-62380. Hence, it has been replaced by IEC 61709 [20] providing a general guideline for failure rate prediction under different operating conditions. In all the mentioned handbook methods, the failure mechanisms are not appropriately modeled and the end-of-life of components is not predicted under the given operating conditions.

Due to the above-mentioned issues, wear-out failure prediction approaches in converter components based on the physics of failures have been presented recently in [18] and [32]-[33][34][35]. According to this approach, the converter reliability is estimated based on potential failure mechanisms of its components. Strength-stress analysis [36] is then performed to predict the failure probability of each potential failure mechanism. The applied stress-such as the converter loading and climate condition fluctuations-over the device is compared to its strength to predict the failure probability. To obtain the components strength, various lifetime models are available in the literature [37], [38]. Using an appropriate lifetime model depends on the availability of model parameters value for selected devices. 
Employing an accurate lifetime model will result in precise reliability prediction which is more applicable for warranty logistics and maintenance. On the other hand, reliability as a long-term performance indicator can be used for comparing different alternatives and selecting the best option in most engineering systems [39]. Since the reliability of different alternatives is relatively compared with together, hence, using the same lifetime model even with low accuracy can properly help in decision making among different alternatives.

In this article, the reliability index is used to compare the performance of two switching schemes. Therefore, the converter reliability is predicted based on wear-out models of its vulnerable components such as capacitors and semiconductor devices. The commonly used lifetime for wear-out modeling of these devices is provided in [36], [37], and [40], while other lifetime models can be used if the lifetime parameter values are available.

The lifetime of electrolytic capacitors are modeled by [41]

$$
L_{o}=L_{r} \cdot 2^{\frac{T_{r}-T_{o}}{n_{1}}}\left(\mathrm{~V} \_\mathrm{o} / \mathrm{V} \_\mathrm{r}\right)^{-n_{2}}
$$

where $L_{r}$ is the rated lifetime under rated voltage of $V_{r}$ and rated capacitor temperature of $T_{r}$, and $L_{o}$ is the capacitor lifetime under operating voltage of $V_{o}$ and operating temperature of $T_{o}$. The exponent of $n_{1}$ follows the industry well-established $10-\mathrm{K}$ rule from Arrhenius in which a $10-\mathrm{K}$ temperature decrement will double the lifetime [41]. Moreover, the exponent $n_{2}$ models the dependency of a lifetime on the applied voltage during operation. Applying lower voltage will cause lower stress to the capacitor dielectric. Operating a capacitor close to its rated voltage will cause more electrolyte consumption due to the self-healing of the small flaws in the dielectric. Thus, the lower operating voltage will extend the capacitor lifetime. The impact of voltage on the capacitor lifetime is modeled by the power-law as given in (25). According to [41], different manufacturers provided various values for exponent $n_{2}$ in (25). Moreover, [41] provides moderate values for $n_{2}$ depending on the applied voltage as given in (26), where $K_{v}=V_{o} / V_{r}$

$$
n_{2}= \begin{cases}3, & 0.5 \leq K_{v}<0.8 \\ 5, & 0.8 \leq K_{v} \leq 1\end{cases}
$$

Furthermore, the number of cycles to failure $N_{f}$ in semiconductor devices are obtained by using [42]

$$
N_{f}=A \cdot \Delta T_{j}^{a_{T}} \cdot \exp \left(\frac{\mathrm{b}_{\mathrm{T}}}{\mathrm{T}_{\mathrm{jm}}}\right) \cdot\left(\frac{\mathrm{t}_{\mathrm{on}}}{1.5}\right)^{-0.3}
$$

where $\Delta T$ and $T$, respectively, are the junction temperature swing and its mean value, and $t_{\text {on }}$ is the temperature cycle rise time. $A, a_{T}$, and $b_{T}$ are constants obtained from aging tests.

Following the lifetime models in (25) and (27), the capacitor temperature and voltage, as well as the semiconductor devices' junction temperature, should be found for the whole mission profile. Thereby, 
at first, the converter is simulated under different operational conditions, and the lifetime-related variables are obtained and stored in lookup tables as shown in Fig. 7(a). Afterward, the annual mission profile is translated into the lifetime variables as shown in Fig. 7(b).

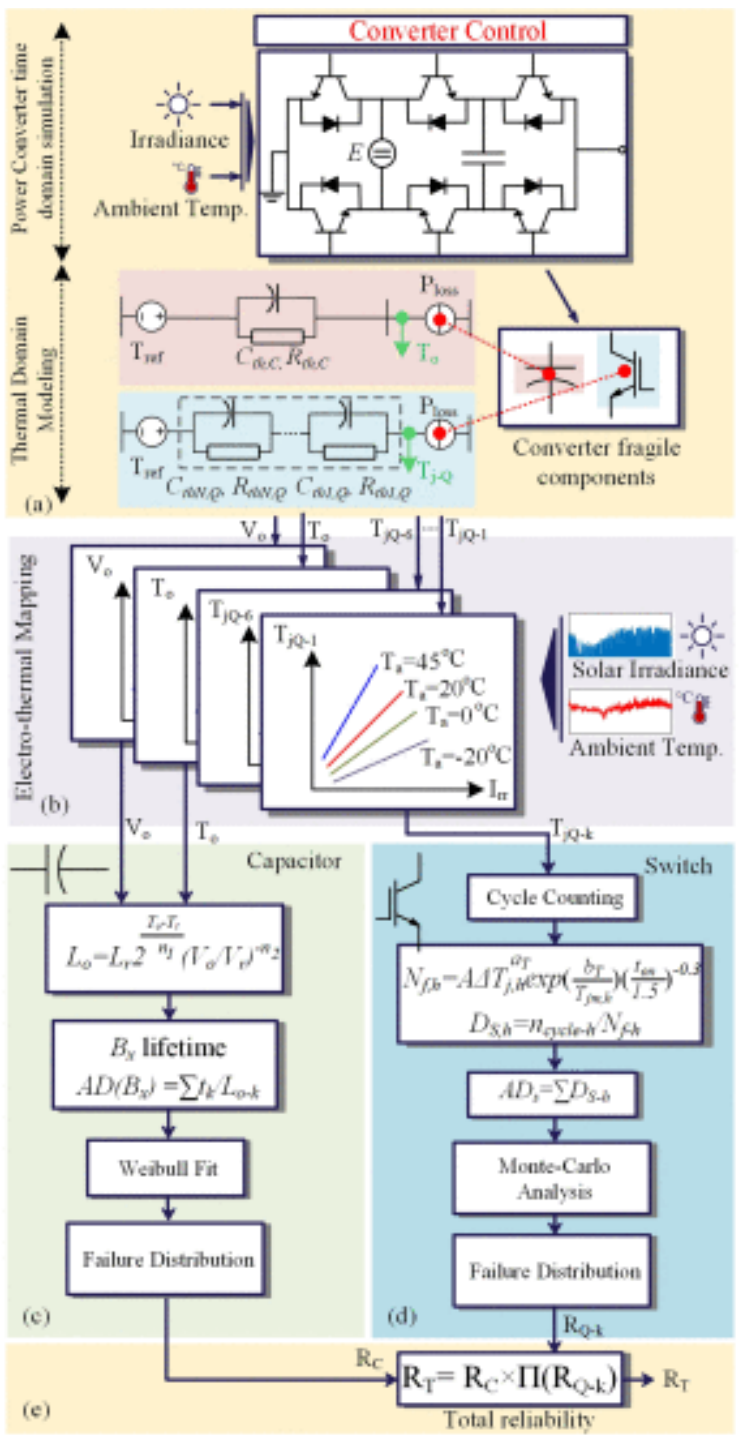

Fig. 7. Reliability prediction process for power converters. (a) Electro-thermal simulation. (b) Electro-thermal mapping. (c) Capacitor wear-out prediction. (d) Semiconductor device wear-out prediction. (e) Total reliability prediction.

The capacitor reliability is estimated by adapting the test data as shown in Fig. 7(c) [43]. The failure distribution of electrolytic capacitors is provided in [44] for the rated lifetime of $5000 \mathrm{~h}$ and an uppercategory temperature of $105^{\circ} \mathrm{C}$, which is modeled by the Weibull distribution with $\alpha=6804 \mathrm{~h}$ and $\beta=5.12$. The failure distribution under operating condition is obtained by calculating the accumulated damage of capacitor $\left(A D_{C}\right)$ as

$$
\mathrm{AD}_{C}=\sum_{k} \frac{t_{k}}{L_{o-k}}
$$


where $t_{k}$ is the time the capacitor operates under $\left(V_{o}, T_{o}\right)$, and $L_{o-k}$ is corresponding operating lifetime obtained by (25). Employing different $B_{x}$ lifetime on (25) will result in different $B_{x}$ accumulated damage. The failure distribution under operating conditions is obtained by fitting the different $B_{x}$ accumulated damage with the Weibull distribution.

Moreover, the semiconductor devices reliability is predicted based on the field data and Monte Carlo simulation as shown in Fig. 7(d) [43]. First, the junction temperature profile is classified into different classes with the number of cycles, temperature swing, and its average value. Next, the damage of the device associated with each class is calculated by dividing the applied cycles to the number of cycles to failure obtained by (27). Hence, the total accumulated damage of semiconductor devices $\left(A D_{S}\right)$ can be obtained as

$$
\mathrm{AD}_{S}=\sum_{h} \frac{n_{\text {cycle }-h}}{N_{f-h}}
$$

The lifetime of the device is equal to the reciprocal of the $A D_{s}$. In order to consider the impact of uncertainties of the lifetime model in (27) and the thermal model of devices, the Monte Carlo simulation is adopted to find out the $\mathrm{AD}_{s}$ considering the variations on different parameters. Hence, the failure distribution can be obtained by fitting the $\mathrm{AD}_{s}$ with the Weibull distribution. The details of the procedure have been explained in [15]. From an operation point of view, failure of any component may cause converter shutdown. As a result, the total converter reliability can be modeled by a series connection of its components according to reliability network modeling. Hence, as shown in Fig. 7(e), the total converter reliability $R_{T}$ is obtained by

$$
R_{T}=R_{C} \times \prod_{j=1}^{6} R_{Q-j} .
$$

where $R_{c}$ is the reliability of the capacitor, and $R_{Q-j}$ is the reliability of $j$ th switch. Notably, the power diodes may have an inconsiderable effect since the converter is operated under a unity power factor. Thus, their impact is neglected. Moreover, the impact of other components and factors such as software reliability is neglected in the reliability prediction, while it can be easily incorporated by a suitable reliability model. This is because according to the filed returned data and industrial experiences, the capacitors and power semiconductors are the most fragile components of power converters [28], [37], [45]-[46][47][48]. Hence, they play a dominant role in the reliability of a converter. On the other hand, the industrial experiences show that these two components are prone to wear-out failures as well [19], [21], [37], [49]-[50][51][52][53]; thus, the converter reliability and life expectancy remarkably depend on the lifetime model of capacitors and semiconductor devices. Therefore, in this article, the reliability and end-of-life of converter under different switching schemes are examined by using the lifetime model of its dominant components. Considering other factors such 
as software reliability, catastrophic failures, and so on can affect the converter reliability, but they are not affected by the switching scheme. Thereby, in this article, the impact of other factors is not taken into consideration.

\section{SECTION IV. Numerical Analyses of the PUC Converter Reliability for Various Applications}

In this section, the reliability performance of the PUC converter is evaluated for two different photovoltaic (PV) and ac microgrid applications.

\section{A. Reliability Prediction of the PUC Converter for PV Applications}

As already mentioned, the converter reliability depends on its application. Hence, without losing the generality, the PUC converter reliability is estimated for a PV application with $2.2 \mathrm{~kW}$ rated capacity. Furthermore, the impact of the proposed switching scheme on the converter reliability is illustrated in a home microgrid application. The first case is discussed in detail, while in the second case, the final results are provided. Both cases show the reliability enhancement employing the proposed switching algorithm. The converter specifications and the PV array parameters are summarized in Table II. The annual solar irradiance and ambient temperature measured in a region of Denmark are shown in Fig. 8.

TABLE II Main Parameters of the Implemented PUC Converter for Reliability Study and Experimental Verification

\begin{tabular}{|c|c|c|}
\hline & Parameter & Value \\
\hline & Rated power & $2.2 \mathrm{~kW}$ \\
\hline & Switching frequency & $10 \mathrm{kHz}$ \\
\hline & PUC DC link voltage (MPPT Output) & $230 \mathrm{~V}$ \\
\hline & PUC DC capacitor voltage & $115 \mathrm{~V}$ \\
\hline & RL test load & $R=40 \Omega, L=20 \mathrm{mH}$ \\
\hline & Power Switch & IGBJON60T \\
\hline \multirow[t]{6}{*}{ 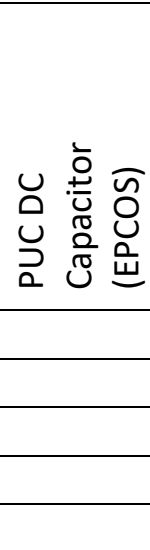 } & \begin{tabular}{|c} 
Capacity \\
Rated voltage \\
ESR \\
$20 \mathrm{kHz}, 80^{\circ} \mathrm{C}$ \\
Thermal resistance \\
Thermal time constant
\end{tabular} & $\begin{array}{l}680 \mathrm{uF} \\
250 \mathrm{~V} \\
0.05 \Omega \\
21 \mathrm{~K} / \mathrm{W} \\
10 \mathrm{~min}\end{array}$ \\
\hline & PV panel type: SUNPOWER & $S P R-220-B L K-1$ \\
\hline & PV panel rated power & $220 W$ \\
\hline & No. series connection & 5 \\
\hline & No. parallel connection & 2 \\
\hline & MPPT Algorithm & Perturb \& Observation \\
\hline
\end{tabular}




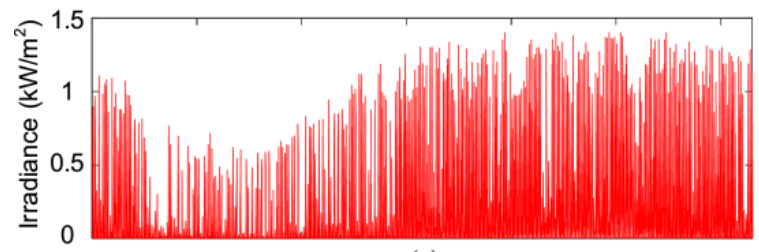

(a)

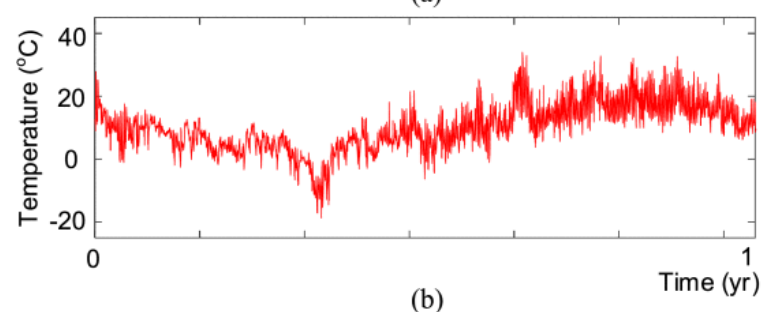

Fig. 8. (a) Annual solar irradiance and (b) ambient temperature measured in Denmark [43].

The accumulated damage of converter components is calculated based on (28) and (29) and the thermal parameters of its components as given in Table II. The damage of components is shown in Fig. 9 in which the capacitor damage is decreased from 0.0594 to 0.0464 by employing the proposed switching scheme. Furthermore, the damage of $S_{3}, S_{5}$ is higher than $S_{2}, S_{6}$ and $S_{1}, S_{4}$ by utilizing the presented switching patterns in [9]-[10][11]. This shows that the power loss and thermal stress is not evenly distributed over the power switches. However, by employing the proposed scheme, the damage of $S_{3}, S_{5}$ is decreased by 0.0190 . Hence, the damages and thermal stresses are almost equally distributed among the switches. As another consequence, employing the proposed switching scheme can reduce the damage of highly stressed components, i.e., capacitor and $S_{3}, S_{5}$ as shown in Fig. 9. Therefore, the overall converter reliability will be improved.

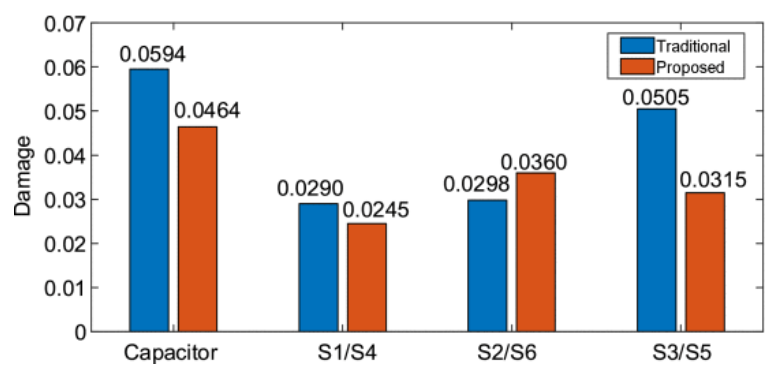

Fig. 9. Annual accumulated damage of different converter components under traditional and proposed switching schemes.

Furthermore, the overall converter reliability is shown in Fig. 10(c). As it is presented in Fig. 10(c), the converter reliability after 10 years of operation can be improved from $89.7 \%$ to $96.5 \%$ by employing the proposed switching scheme. Furthermore, the converter $B_{1}$ lifetime, which is the lifetime at $99.0 \%$ reliability, is improved by almost 2 years under the proposed switching algorithm. Therefore, the converter $B_{1}$ lifetime is extended by $35 \%$ under the proposed switching scheme. As a result, the proposed switching strategy can considerably enhance the PUC converter reliability at its long-term performance indicator. 

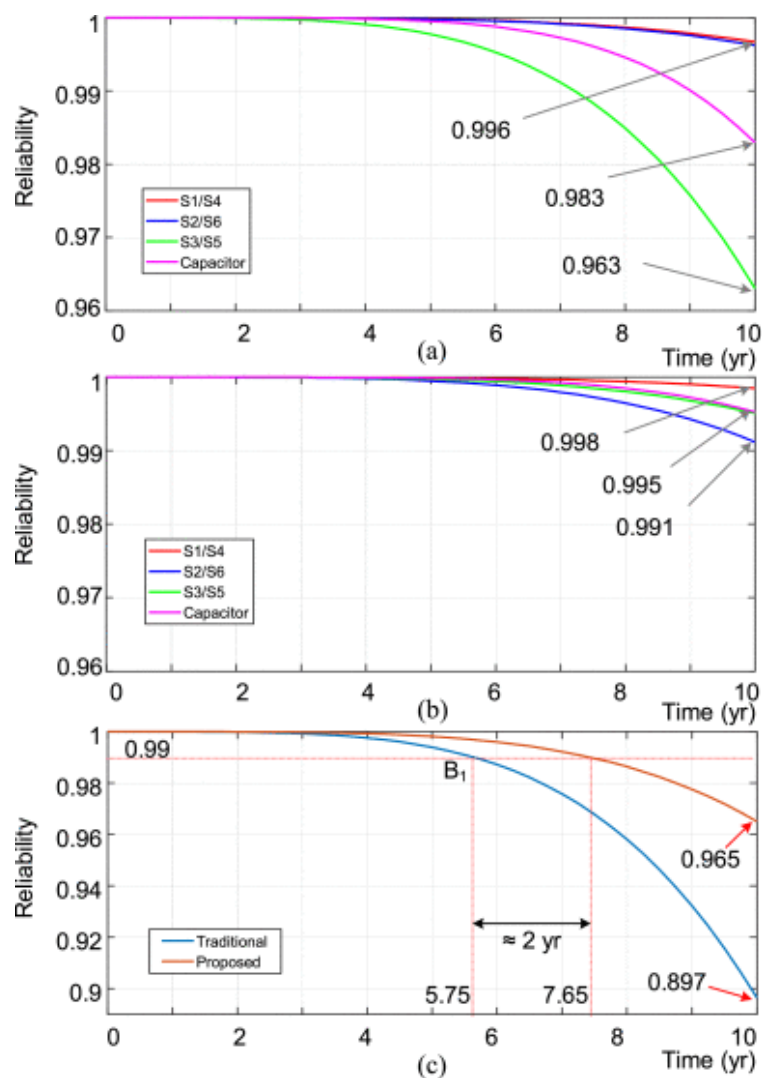

Fig. 10. Reliability of the PUC converter components under the mission profile shown in Fig. 8 and by employing (a) traditional switching schemes, (b) proposed switching scheme, and (c) total PUC converter reliability.

\section{B. Reliability Prediction of the PUC Converter for AC Microgrid Applications}

In order to evaluate the converter reliability under different mission profiles, another application is considered and the converter reliability using the traditional and the proposed switching schemes are illustrated. The converter is used as an energy conversion stage in an ac home microgrid as shown in Fig. 11(a). The prime energy course can be any types of dc source such as PV + battery system, wind + battery system, fuel cell stack, or even dc utility grid, which is one of the solutions for future dc distribution systems. The converter has the same specifications summarized in Table II. The annual home load profile is shown in Fig. 11(b). Furthermore, the ambient temperature is considered to be similar to the last case study as shown in Fig. 8(b). Like the previous case, the converter reliability under the home load profile is predicted. 


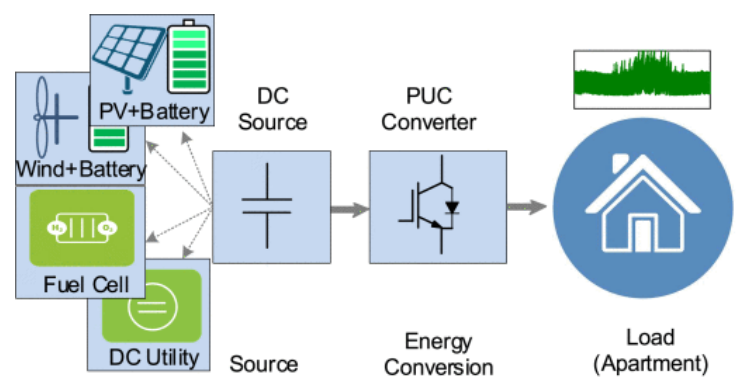

(a)

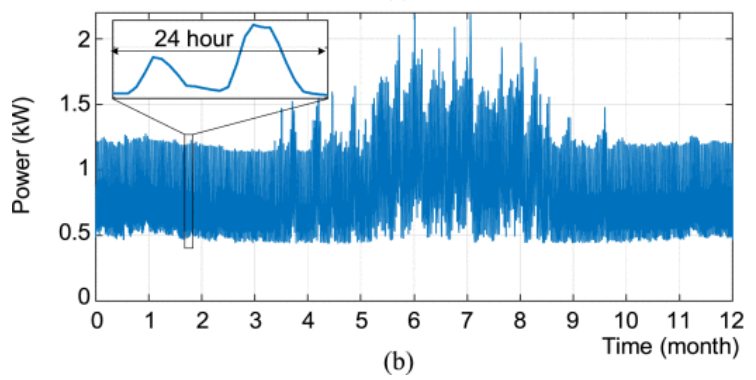

Fig. 11. Home ac microgrid. (a) Microgrid structure. (b) Apartment load profile.

The total converter reliability is shown in Fig. 12. Following Fig. 12, the converter reliability after 10 years of operation is $96.4 \%$ and $98.9 \%$ for the traditional and proposed switching schemes. Thus, using the proposed scheme, the overall converter reliability is improved by $2.5 \%$ under the given mission profile in Fig. 11(b). Moreover, the converter $B_{1}$ lifetime using the traditional and proposed switching schemes is 7.25 and 10 years, respectively. Thus, employing the proposed switching scheme will enhance the $B_{1}$ lifetime by $27.5 \%$.

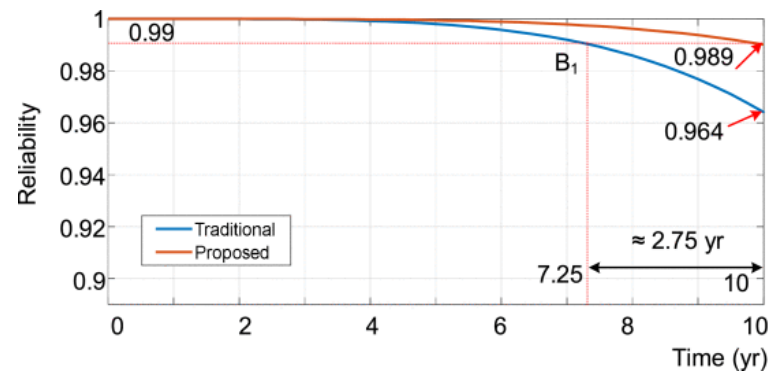

Fig. 12. Reliability of the PUC converter components under an apartment load profile using the traditional and proposed switching scheme.

These two case studies with the PV and microgrid applications show that the proposed switching scheme enhances the converter reliability compared to the traditional method. Thus, the lifetime of the converter can be extended by employing the proposed approach. Notably, the converter reliability depends on its mission profile, where this can be seen from reliability results in Figs. 10(c) and 12 for two different mission profiles. Thereby, the reliability improvement for different applications is not identical. However, both case studies show that the converter reliability is relatively improved by using the proposed switching algorithm. 


\section{SECTION V. Experimental Results and Comparison}

The experimental prototype of the PUC converter has been implemented to evaluate the performance and viability of the proposed single-carrier sensor-less modulation method. Fig. 13 presents the image of the implemented experimental prototype of the PUC converter. Parameters of the implemented PUC converter are presented in Table II.

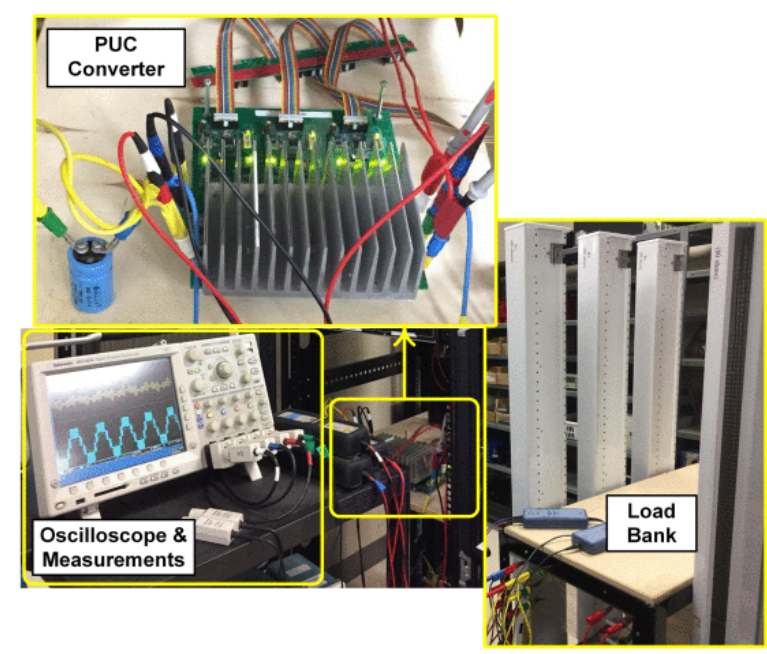

Fig. 13. Implemented experimental setup of the PUC converter.

Both the proposed and traditional PWM methods have been applied to the PUC converter. The experimental results and thermal images of the PUC converter employing the proposed and traditional switching patterns are presented and compared. As presented in Table II, the switching frequency of the PUC converter is set to $f_{\mathrm{SW}}=10 \mathrm{kHz}$. The dead-time is set to $500 \mathrm{~ns}$ by using integrated hardware dead-time generator.

Fig. 14 presents the PUC converter output voltage, its fast Fourier transform (FFT) analysis, load current, as well as the dc capacitor voltage and current by employing the proposed modulation method. As shown in Fig. 14, the first switching harmonic cluster of the output voltage is shifted to 2 . $f_{\mathrm{SW}}=20 \mathrm{kHz}$ and the odd multiples of the switching harmonic clusters are eliminated from the output voltage. Moreover, the PUC dc capacitor voltage ripple is negligible, and with regard to the PUC dc capacitor current, the charge and discharge of the dc capacitor are balanced in each PWM period.

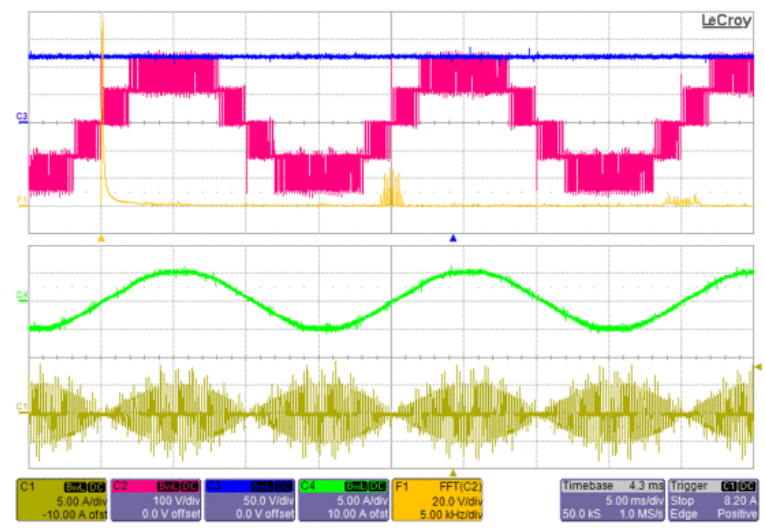


Fig. 14. Output voltage (C2: $100 \mathrm{~V} /$ div), its FFT analysis (F1: vertical: $20 \mathrm{~V} /$ div; horizontal: $5 \mathrm{kHz} /$ div), load current (C4: $5 \mathrm{~A} /$ div), the PUC dc capacitor voltage (C3: $50 \mathrm{~V} /$ div), and the PUC dc capacitor current (C1: $5 \mathrm{~A} / \mathrm{div})$ by applying the proposed modulation method.

On the other hand, the PUC converter output voltage, its FFT analysis, load current, as well as the dc capacitor voltage and current by employing the traditional modulation method are presented in Fig. 15. As depicted in Fig. 15, the first switching harmonic cluster of the output voltage is at $f_{\mathrm{SW}}=$ $10 \mathrm{kHz}$. Moreover, the PUC dc capacitor voltage ripple is about $60 V_{P-P}$ and the charge and discharge of the dc capacitor are balanced in each fundamental period. Hence, applying the proposed single-carrier sensor-less PWM method results in a substantial reduction in the PUC dc capacitor voltage ripple, a notable decrease in sensitivity of the dc capacitor voltage ripple to load, and doubling the first switching harmonic cluster frequency which leads to halving the output passive filter components value.

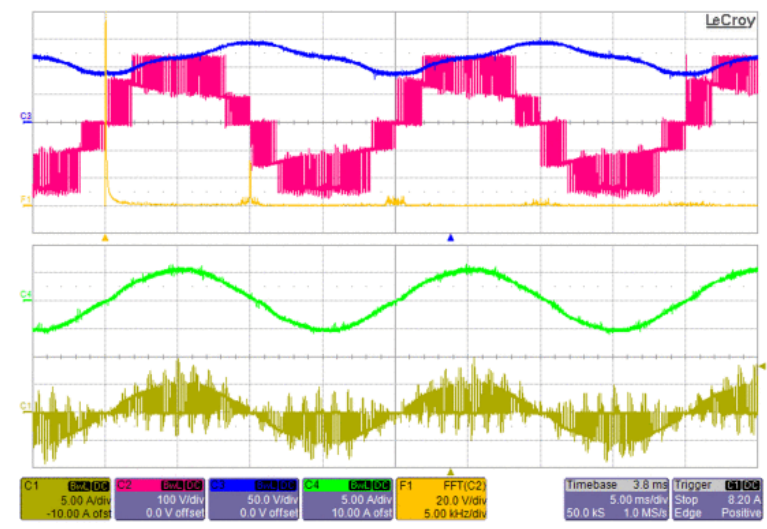

Fig. 15. Output voltage (C2: $100 \mathrm{~V} /$ div), its FFT analysis (F1: vertical: $20 \mathrm{~V} /$ div; horizontal: $5 \mathrm{kHz} /$ div), load current (C4: $5 \mathrm{~A} /$ div), the PUC dc capacitor voltage (C3: $50 \mathrm{~V} /$ div), and the PUC dc capacitor current (C1: $5 \mathrm{~A} /$ div) by applying the traditional modulation method.

Fig. 16 presents the transient and steady-state voltage of the PUC dc capacitor during converter startup by applying the proposed method. As depicted in Fig. 16, the transient time of the capacitor voltage is $800 \mathrm{~ms}$ and the capacitor is automatically regulated to its desired value. On the other hand, the transient and steady-state voltage of the PUC dc capacitor during converter start-up by applying the traditional method is shown in Fig. 17. As presented in Fig. 17, the transient time of the capacitor voltage is $1600 \mathrm{~ms}$ and the capacitor voltage ripple is about $60 \mathrm{VP}-P$. Therefore, applying the proposed single-carrier sensor-less PWM method remarkably improves the dynamic performance of the PUC converter during start-up and notably decreases the dc capacitor voltage ripple. 


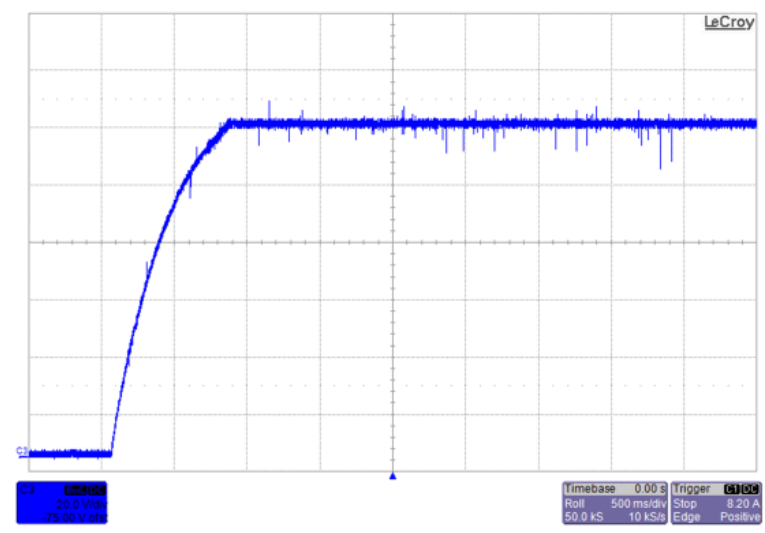

Fig. 16. Transient and steady-state voltage of the PUC dc capacitor during converter start-up by applying the proposed modulation method.

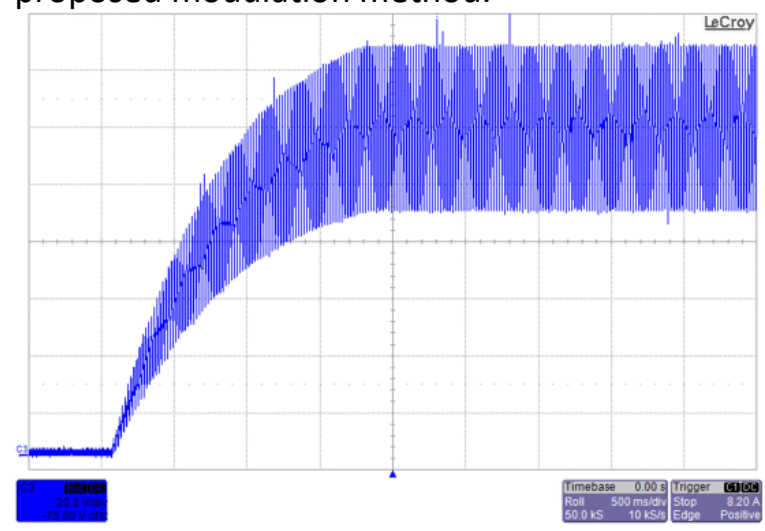

Fig. 17. Transient and steady-state voltage of the PUC dc capacitor during converter start-up by applying the traditional modulation method.

Fig. 18 presents the thermal image of the PUC converter controlled by the proposed modulation method. As illustrated in Fig. 18, the temperatures of $S_{2}, S_{3}, S_{5}$, and $S_{6} \mathrm{HF}$ power switches are approximately equal. Moreover, the measured min and max temperatures of the PUC converter are 31.8 and $38.4{ }^{\circ} \mathrm{C}$, respectively. Thus, the temperature difference between the coldest and hottest spots of the PUC converter is only $6.6^{\circ} \mathrm{C}$. On the other hand, the thermal image of the PUC converter controlled by the traditional modulation method is depicted in Fig. 19. As shown in Fig. 19, the temperatures of $S_{3}, S_{5} \mathrm{HF}$ switches are much higher than the temperatures of $S_{2}, S_{6} \mathrm{HF}$ switches. In addition, the measured min and max temperatures of the PUC converter are 30.0 and $48.0{ }^{\circ} \mathrm{C}$, respectively. Therefore, the temperature difference between the coldest and hottest spots of the PUC converter is $18^{\circ} \mathrm{C}$. 


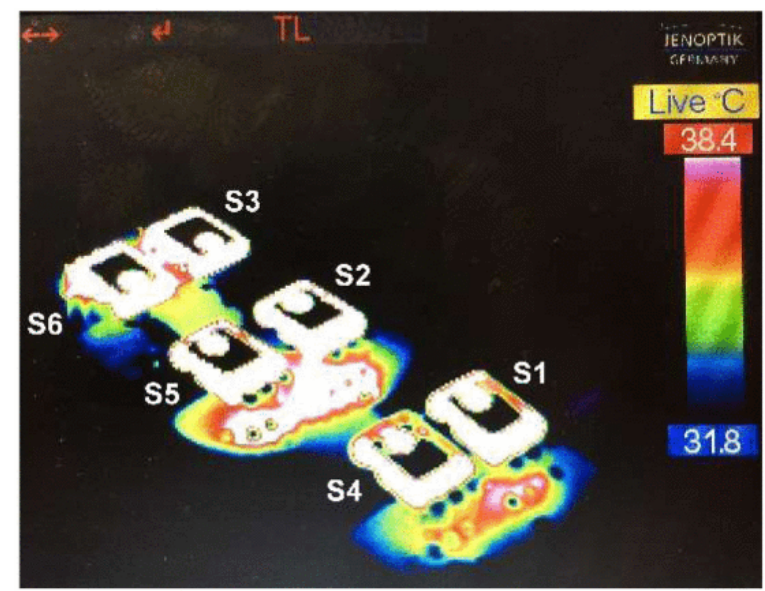

Fig. 18. Thermal image of the PUC converter by applying the proposed modulation method.

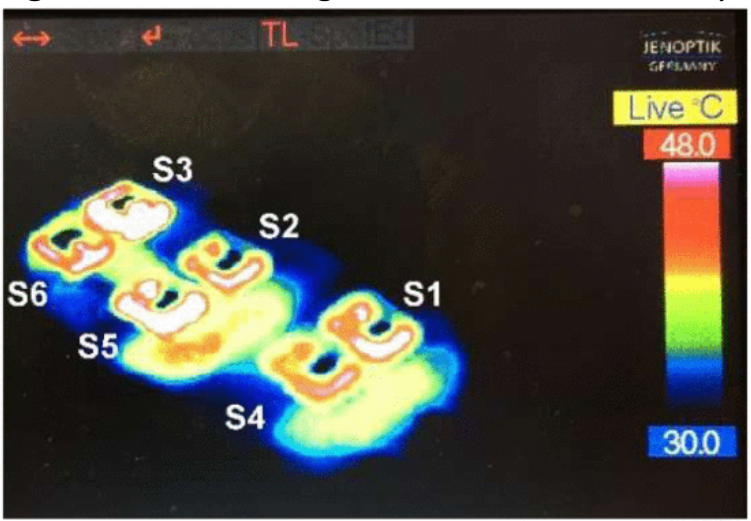

Fig. 19. Thermal image of the PUC converter by applying the traditional modulation method.

Moreover, the distribution of the conduction and switching power losses of the PUC converter controlled by the conventional and the proposed switching pattern are presented in Table III. As illustrated in Table III, the conduction and switching power losses are evenly distributed over HF power switches in the PUC converter by applying the proposed modulation method. However, the conduction and switching power losses are not equally distributed among HF power switches by employing the conventional switching method. Moreover, the total power loss and efficiency of the PUC converter controlled by both the conventional and proposed switching methods are presented in Table III. Hence, applying the proposed single-carrier sensor-less PWM method leads to even distribution of the power loss among HF switches, decrease of the temperature difference between various parts of the PUC converter, and accordingly improvement of the converter reliability and lifetime. 
TABLE III Distribution of the Conduction and Switching Losses of the PUC Converter Controlled by the Traditional and Proposed Methods

\begin{tabular}{|c|c|c|c|c|c|c|c|c|c|}
\hline $\begin{array}{l}\text { Switching } \\
\text { Method }\end{array}$ & $\begin{array}{l}\text { Total } \\
\text { (watt) }\end{array}$ & $\begin{array}{l}\text { Conduction } \\
\text { Power Loss (watt) }\end{array}$ & & & $\begin{array}{l}\text { Switching } \\
\text { Power Loss } \\
\text { (watt) }\end{array}$ & & & $\begin{array}{l}\text { Simulated } \\
\text { Efficiency (\%) }\end{array}$ & $\begin{array}{l}\text { Measured } \\
\text { Efficiency (\%) }\end{array}$ \\
\hline & & $P_{\text {Cond_s1 }}$ & $P_{\text {Cond_s2 }}$ & $P_{\text {Cond_s3 }}$ & $P_{S W_{-} S 1}$ & $P_{S W_{S 2}}$ & $P_{S W \_S 3}$ & & \\
\hline $\begin{array}{l}\text { Conventional } \\
\text { Method } \\
(P=2.2 \mathrm{~kW}) \\
\end{array}$ & 43.5 & 14.8 & 11.2 & 14.8 & $\approx 0$ & 2.2 & 0.5 & 98.02 & 97 \\
\hline $\begin{array}{l}\text { Proposed } \\
\text { Method } \\
(P=2.2 \mathrm{~kW})\end{array}$ & 42.1 & 14.5 & 12.5 & 12.5 & $\approx 0$ & 1.3 & 1.3 & 98.08 & 97 \\
\hline
\end{tabular}


Comparison between the performance of the PUC converter controlled by the proposed single-carrier sensor-less and the traditional PWM methods from aspects of the PUC dc capacitor voltage ripple, accumulated damages of power switches $\left(\sigma_{\mathrm{AD}-S}\right)$, the standard deviation of accumulated damages of all the PUC converter components $\left(\sigma_{\mathrm{AD}}\right), B_{1}$ lifetime, $R_{10}$ reliability, and the computational burden is illustrated in Fig. 20. As depicted in Fig. 20, the proposed single-carrier sensor-less modulation method has superior performance in comparison to the traditional PWM methods for the PUC converter. Regarding the presented experimental results, and the converter performance diamond in Fig. 20, the main advantages of the proposed switching method are as follows:

1. notable reduction of the dc capacitor voltage ripple;

2. equal loss distribution between HF power devices;

3. higher reliability and longer lifetime;

4. faster self-balancing of dc capacitor voltage at start-up;

5. eliminating odd multiples of the output voltage switching harmonic clusters;

6. halving the required output passive filter components values;

7. easy to implement.

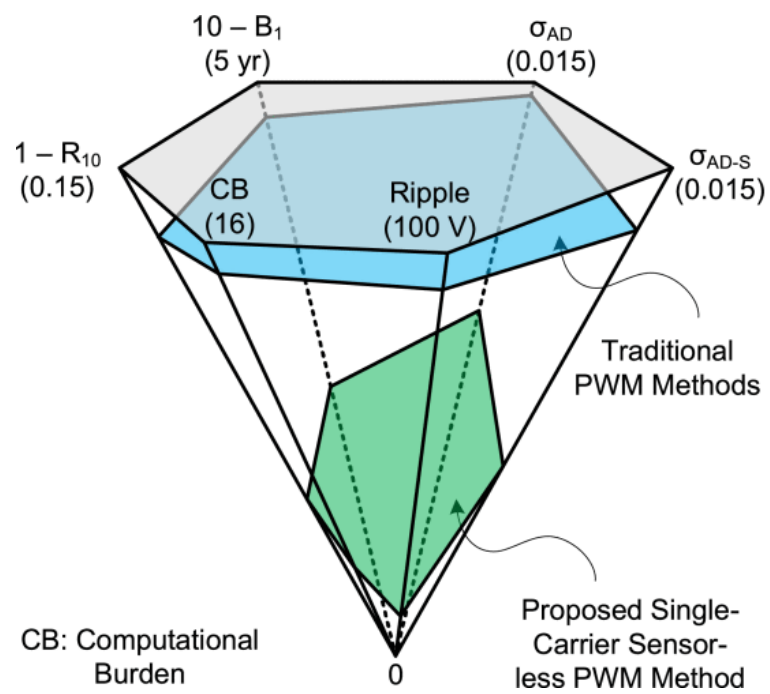

Fig. 20. PUC converter performance diamond by applying the proposed single-carrier sensor-less and traditional PWM methods. Diamond axes: 1) Ripple (100 V): the PUC dc capacitor voltage ripple (range: 0-100 V); 2$) \sigma_{\mathrm{AD}-S}$ (0.015): standard deviation of accumulated damages of power switches (range: $0-0.015)$; 3) $\sigma_{\mathrm{AD}}(0.015)$ : standard deviation of accumulated damages of all the PUC converter components (range: $0-0.015) ; 4) 10-B_{1}(5$ years): the PUC converter lifetime degradation (range: $0-5$ years); 5) $1-R_{10}(0.15)$ : the PUC converter reliability degradation after 10 years of operation (unreliability) (range: $0-0.15)$; 6) CB (16): the utilized method computational burden from aspect of the number of PWM comparators, If-Else loops, and logic gates (range: 0-16).

Comparison between the proposed single-carrier sensor-less modulation method and the introduced methods in [9], [11]-[12][13] for PUC converter is illustrated in Table IV. As presented in Table IV, the proposed single-carrier sensor-less modulation method is easy to implement, and it has much less computational burden in comparison to other modulation methods for PUC converter. Moreover, the value of capacitor depends on switching frequency and is remarkably decreased by employing the 
proposed modulation method. In addition, the value of capacitor can be more reduced by increasing the switching frequency.

TABLE IV Comparison Between the Proposed Single-Carrier Sensor-Less Modulation Method and the Presented Methods in [9] and [11]-[13]

\begin{tabular}{|c|c|c|c|c|c|}
\hline \multirow[t]{2}{*}{ PWM Method } & $\begin{array}{l}\text { Capacitor } \\
\text { Value }\end{array}$ & $\begin{array}{l}\text { Computational } \\
\text { Burden }\end{array}$ & & & \\
\hline & & $\begin{array}{l}\text { No. of PWM } \\
\text { Carriers } \\
\text { (Timers) }\end{array}$ & $\begin{array}{l}\text { No. of If-Else } \\
\text { Loops }\end{array}$ & $\begin{array}{l}\text { No. of Logic } \\
\text { Gates }\end{array}$ & Total \\
\hline $\begin{array}{l}\text { Proposed } \\
\text { Method }\end{array}$ & $\frac{I_{\text {peak }}}{V_{\text {ripple }} \times 2 f_{S W}}$ & 1 & - & - & 1 \\
\hline [9] & $\frac{I_{\text {peak }}}{V_{\text {ripple }} \times 2 f_{0}}$ & 4 & 6 & 5 & 15 \\
\hline$[11\}$ & $\frac{I_{\text {peak }}}{V_{\text {ripple }} \times 2 f_{0}}$ & 4 & 12 & - & 16 \\
\hline [12] & $\frac{I_{\text {peak }}}{V_{\text {ripple }} \times 2 f_{S W}}$ & 2 & - & 6 & 8 \\
\hline [13] & $\frac{I_{\text {peak }}}{V_{\text {ripple }} \times 2 f_{S W}}$ & 2 & - & 6 & 8 \\
\hline
\end{tabular}

\section{SECTION VI. Conclusion}

The single-carrier sensor-less PWM method was proposed for the PUC converter. It comprises only one PWM carrier signal, and two suggested pseudo reference functions. Applying the proposed method led to notable reduction in the capacitor voltage ripple, faster sensor-less capacitor voltage balancing, simplified control circuit, amended output voltage spectrum, smaller output passive filter, equal power losses distribution between power devices, improved reliability, and increased lifetime. Therefore, the proposed single-carrier sensor-less modulation method remarkably improved the performance of the PUC converter and notably simplified implementation of the switching pattern. Provided experimental results and comparisons validated the viability and effectiveness of the proposed modulation method.

\section{References}

1. J. Rodriguez, L. Jih-Sheng and P. Fang Zheng, "Multilevel inverters: A survey of topologies controls and applications", IEEE Trans. Ind. Electron., vol. 49, no. 4, pp. 724-738, Aug. 2002.

2. S. Kouro et al., "Recent advances and industrial applications of multilevel converters", IEEE Trans. Ind. Electron., vol. 57, no. 8, pp. 2553-2580, Aug. 2010.

3. M. Abarzadeh and K. Al-Haddad, "An improved active-neutral-point-clamped converter with new modulation method for ground power unit application", IEEE Trans. Ind. Electron., vol. 66, no. 1, pp. 203-214, Jan. 2019.

4. Y. Ounejjar, K. Al-Haddad and L. A. Gregoire, "Packed U cells multilevel converter topology: Theoretical study and experimental validation", IEEE Trans. Ind. Electron., vol. 58, no. 4, pp. 1294-1306, Apr. 2011. 
5. H. Vahedi and K. Al-Haddad, "PUC5 inverter-A promising topology for single-phase and three-phase applications", Proc. IECON 42nd Annu. Conf. IEEE Ind. Electron. Soc., pp. 6522-6527, Oct. 2016.

6. Y. Ounejjar, K. Al-Haddad and L. A. Dessaint, "A novel six-band hysteresis control for the packed U cells seven-level converter: Experimental validation", IEEE Trans. Ind. Electron., vol. 59, no. 10, pp. 3808-3816, Oct. 2012.

7. M. Trabelsi, S. Bayhan, K. A. Ghazi, H. Abu-Rub and L. Ben-Brahim, "Finite-control-set model predictive control for grid-connected packed-U-cells multilevel inverter", IEEE Trans. Ind. Electron., vol. 63, no. 11, pp. 7286-7295, Nov. 2016.

8. J. I. Metri, H. Vahedi, H. Y. Kanaan and K. Al-Haddad, "Real-time implementation of model-predictive control on seven-level packed U-cell inverter", IEEE Trans. Ind. Electron., vol. 63, no. 7, pp. 4180-4186, Jul. 2016.

9. H. Vahedi, P. A. Labbé and K. Al-Haddad, "Sensor-less five-level packed U-cell (PUC5) inverter operating in stand-alone and grid-connected modes", IEEE Trans. Ind. Inform., vol. 12, no. 1, pp. 361-370, Feb. 2016.

10. S. Arazm, H. Vahedi and K. Al-Haddad, "Space vector modulation technique on single phase sensorless PUC5 inverter and voltage balancing at flying capacitor", Proc. IEEE IECON, pp. 4504-4509, 2018.

11. S. Arazm, H. Vahedi and K. Al-Haddad, "Phase-shift modulation technique for 5-level packed U-cell (PUC5) inverter", Proc. IEEE CPE-POWERENG, pp. 1-6, 2018.

12. M. Abarzadeh, H. Vahedi, K. Al-Haddad and M. R. Dehbozorgi, "Sensor-less logic-equation-based modulation method for grid-connected PUC5 converter", Proc. IEEE IECON, pp. 4486-4491, 2018.

13. M. Abarzadeh, H. Vahedi and K. Al-Haddad, "Fast sensor-less voltage balancing and capacitor size reduction in PUC5 converter using novel modulation method", IEEE Trans. Ind. Inform., vol. 15, no. 8, pp. 4394-4406, Aug. 2019.

14. S. Peyghami, P. Davari and F. Blaabjerg, "System-level reliability-oriented power sharing strategy for DC power systems", IEEE Trans. Ind. Appl., vol. 55, no. 5, pp. 4865-4875, Sep./Oct. 2019.

15. S. Peyghami, H. Wang, P. Davari and F. Blaabjerg, "Mission-profile-based system-level reliability analysis in DC microgrids", IEEE Trans. Ind. Appl., vol. 55, no. 5, pp. 5055-5067, Sep./Oct. 2019.

16. F. Hahn, M. Andresen, G. Buticchi and M. Liserre, "Mission profile based reliability evaluation of building blocks for modular power converters", Proc. IEEE PCIM Eur., pp. 1-7, 2017.

17. S. E. D. León-Aldaco, H. Calleja, F. Chan and H. R. Jiménez-Grajales, "Effect of the mission profile on the reliability of a power converter aimed at photovoltaic applications-A case study", IEEE Trans. Power Electron., vol. 28, no. 6, pp. 2998-3007, Jun. 2013.

18. K. Ma, M. Liserre, F. Blaabjerg and T. Kerekes, "Thermal loading and lifetime estimation for power device considering mission profiles in wind power converter", IEEE Trans. Power Electron., vol. 30, no. 2, pp. 590-602, Feb. 2015.

19. S. Peyghami, Z. Wang and F. Blaabjerg, "Reliability modeling of power electronic converters: A general approach", Proc. IEEE COMPEL, pp. 1-7, 2019.

20. "Electric Components - Reliability - Reference Conditions for Failure Rates and Stress Models for Conversion", IEC Commission Standard IEC 61709: 2017, 2017.

21. "Reliability Data Handbook-Universal Model for Reliability Prediction of Electronics Components PCBs and Equipment", IEC Commission Standard IEC TR 62380, 2006. 
22. Apr. 2020, [online] Available: https://www.fides-reliability.org/.

23. M. Abarzadeh and K. Al-Haddad, "Generalized circuit topology of Qn-Hybrid-NPC multilevel converter with novel decomposed sensor-less modulation method", IEEE Access, vol. 7, pp. 59813-59824, 2019.

24.R. H. Wilkinson, T. A. Meynard and H. d. T. Mouton, "Natural balance of multicell converters: The two-cell case", IEEE Trans. Power Electron., vol. 21, no. 6, pp. 1649-1657, Nov. 2006.

25. R. H. Wilkinson, T. A. Meynard and H. d. T. Mouton, "Natural balance of multicell converters: The general case", IEEE Trans. Power Electron., vol. 21, no. 6, pp. 1658-1666, Nov. 2006.

26. D. G. Holmes and T. A. Lipo, "Pulse width modulation for power converters: Principles and practice" in IEEE Press Series On Power Engineering, Hoboken, NJ, USA:Wiley, 2003.

27. R. Billinton and R. Allan, Reliability Evaluation of Engineering Systems, New York, NY, USA:Plenum Press, 1992.

28. S. Yang, A. Bryant, P. Mawby, D. Xiang, L. Ran and P. Tavner, "An industry-based survey of reliability in power electronic converters", Proc. IEEE Energy Convers. Congr. Expo., pp. 3151-3157, 2009.

29. Y. Song and B. Wang, "Survey on reliability of power electronic systems", IEEE Trans. Power Electron., vol. 28, no. 1, pp. 591-604, Jan. 2013.

30. L. F. Costa and M. Liserre, "Failure analysis of the dc-dc converter: A comprehensive survey of faults and solutions for improving reliability", IEEE Power Electron. Mag., vol. 5, no. 4, pp. 42-51, Dec. 2018.

31. H. Wang, K. Ma and F. Blaabjerg, "Design for reliability of power electronic systems", Proc. IEEE IECON, pp. 33-44, 2012.

32. P. D. Reigosa et al., "Prediction of bond wire fatigue of IGBTs in a PV inverter under a long-term operation", IEEE Trans. Power Electron., vol. 31, no. 10, pp. 3052-3059, Mar. 2016.

33. D. Zhou, H. Wang and F. Blaabjerg, "Mission profile based system-level reliability analysis of DC/DC converters for a backup power application", IEEE Trans. Power Electron., vol. 33, no. 9, pp. 8030-8039, Sep. 2018.

34. F. Blaabjerg, K. Ma, D. Zhou and Y. Yang, "Mission profile-oriented reliability design in wind turbine and photovoltaic systems" in Reliability of Power Electronic Converter Systems, London: U.K.:Institution of Engineering and Technology, pp. 355-390, 2015.

35. M. Ciappa, F. Carbognani, P. Cova and W. Fichtner, "Lifetime prediction and design of reliability tests for high-power devices in automotive applications", Proc. IEEE Int. Reliab. Phys. Symp., vol. 2003, no. 4, pp. 523-528, 2003.

36. S. Peyghami, Z. Wang and F. Blaabjerg, "A guideline for reliability prediction in power electronic converters", IEEE Trans. Power Electron., vol. 35, no. 10, pp. 10958-10968, Oct. 2020.

37. H. Wang and F. Blaabjerg, "Reliability of capacitors for DC-link applications in power electronic converters-An overview", IEEE Trans. Ind. Appl., vol. 50, no. 5, pp. 3569-3578, Sep. 2014.

38. K. Ma, H. Wang and F. Blaabjerg, "New approaches to reliability assessment: Using physics-offailure for prediction and design in power electronics systems", IEEE Power Electron. Mag., vol. 3, no. 4, pp. 28-41, Dec. 2016.

39. B. M. Ayyub and R. H. McCuen, Probability Statistics and Reliability for Engineers and Scientists, New York, NY, USA:Taylor \& Francis Group, 2015.

40. H. S. Chung, H. Wang, F. Blaabjerg and M. Pecht, Reliability of Power Electronic Converter Systems, London, U.K.:IET, 2016. 
41. A. Albertsen, Electrolytic Capacitor Lifetime Estimation, 2010.

42. R. Bayerer, T. Herrmann, T. Licht, J. Lutz and M. Feller, "Model for power cycling lifetime of IGBT modules-Various factors influencing lifetime", Proc. VDE Int. Conf. Integr. Power Electron. Syst., pp. 1-6, 2008.

43. S. Peyghami, P. Davari, H. Wang and F. Blaabjerg, "The impact of topology and mission profile on the reliability of boost-type converters in PV applications", Proc. IEEE COMPEL, pp. 1-8, 2018.

44. D. Zhou and F. Blaabjerg, "Reliability evaluation of power capacitors in a wind turbine system", Proc. IEEE APEC, pp. 3264-3269, 2018.

45. J. Falck, C. Felgemacher, A. Rojko, M. Liserre and P. Zacharias, "Reliability of power electronic systems: An industry perspective", IEEE Ind. Electron. Mag., vol. 12, no. 2, pp. 24-35, Jun. 2018.

46. K. Fischer et al., "Reliability of power converters in wind turbines: Exploratory analysis of failure and operating data from a worldwide turbine fleet", IEEE Trans. Power Electron., vol. 34, no. 7, pp. 6332-6344, Jul. 2019.

47. M. Wilkinson and B. Hendriks, "Report on wind turbine reliability profiles", 2011.

48. L. M. Moore and H. N. Post, "Five years of operating experience at a large utility-scale photovoltaic generating plant", Prog. Photovolt. Res. Appl., vol. 16, no. 3, pp. 249-259, 2008.

49. R. Wu, F. Blaabjerg, H. Wang, M. Liserre and F. Iannuzzo, "Catastrophic failure and fault-tolerant design of IGBT power electronic converters-An overview", Proc. IEEE IECON, pp. 507-513, 2013.

50. M. Pecht and J. Gu, "Physics-of-failure-based prognostics for electronic products", Trans. Inst. Meas. Control, vol. 31, no. 3, pp. 309-322, 2009.

51. N. Degrenne et al., "A review of prognostics and health management for power semiconductor modules", Proc. Annu. Conf. Prognostics Health Manag. Soc., pp. 1-11, 2015.

52. Y. Luo, F. Xiao, B. Wang and B. Liu, "Failure analysis of power electronic devices and their Show in

53. H. Oh, B. Han, P. McCluskey, C. Han and B. D. Youn, "Physics-of-failure condition monitoring and prognostics of insulated gate bipolar transistor modules: A review", IEEE Trans. Power Electron., vol. 30, no. 5, pp. 2413-2426, May 2015. 